\title{
GERAÇÃO ADICIONAL NA CTE-2 COM GÁS NATURAL PARA REDUÇÃO DE CUSTO DA ENERGIA ELÉTRICA NO GRUPO CSN*
}

\author{
Luiz Antônio da Silva ${ }^{1}$ \\ Mauro Candido de Menezes² \\ Altair Mantesso Ruela ${ }^{3}$ \\ Marcelo José Alves ${ }^{4}$
}

\section{Resumo}

Este trabalho tem como objetivo apresentar os resultados do procedimento de geração de energia elétrica adicional a geração econômica na CTE2 com gás natural, visando a redução de custo no grupo CSN.O estudo foi efetuado através da avaliação dos preços do mercado de curto prazo de energia elétrica e análise do processo de geração da planta, aos quais permitiram diagnosticar as melhores praticas e definir a melhor configuração operacional.Os resultados apresentados foram significativos para as condições de operação, o que representa redução do custo de energia elétrica para o grupo CSN e aumento da segurança operacional da planta da CTE2.

Palavras-chave: Geração; Energia; Grupo.

\section{ADDITIONAL GENERATION CTE - 2 WITH NATURAL GAS TO REDUCE COST OF ELECTRICITY IN CSN GROUP}

\section{Abstract}

This paper present the results of the generation of additional electricity generation in the economic procedure CTE2 with natural gas aimed at reducing costs in Group CSN.O study was performed by evaluating the prices of short-term energy analysis and generation process plant market, which allowed the best practices to diagnose and define the best configuration operational.Os results were significant for the operating conditions, which is reducing the cost of electricity for the CSN group and increased operational safety of the plant CTE2.

Keywords: Energy; Generation; Group.

1 Engenheiro Mecânico, Engenheiro Especialista da Gerencia de Geração de Energéticos, CSN, Volta Redonda, RJ, Brasil.

2 Técnico Telecomunicações, Líder Energético da Gerência de Geração de Energéticos, CSN, Volta Redonda, RJ, Brasil.

3 Bacharel em Matemática, Analista de Processo Sênior da Gerência Geral de Geração de Utilidades, CSN, Volta Redonda, RJ, Brasil.

4 Engenheiro Elétrico, Gerente da Gerência de Participação em Energia, CSN, Volta Redonda, RJ, Brasil. 


\section{INTRODUÇÃO}

O Processo de Geração de Energéticos da Central Termoelétrica 2 (1) é composto por três caldeiras (2) constituídas por tubos especiais de aço refratários e dois turbo geradores, conforme Figura 1, que fazem a geração de vapor para a produção de energia elétrica de $60 \mathrm{HZ}$, Ar Soprado e Vapor de processo para as áreas de produção da Usina Presidente Vargas (UPV) utilizando como insumos água e combustíveis siderúrgicos (gás de alto forno (GAF), gás de aciaria (GLD) e gás de coqueria (GCO)) e combustíveis externos de alto valor agregado (Gás Natural (GN) e Óleo BPF(apenas emergências).

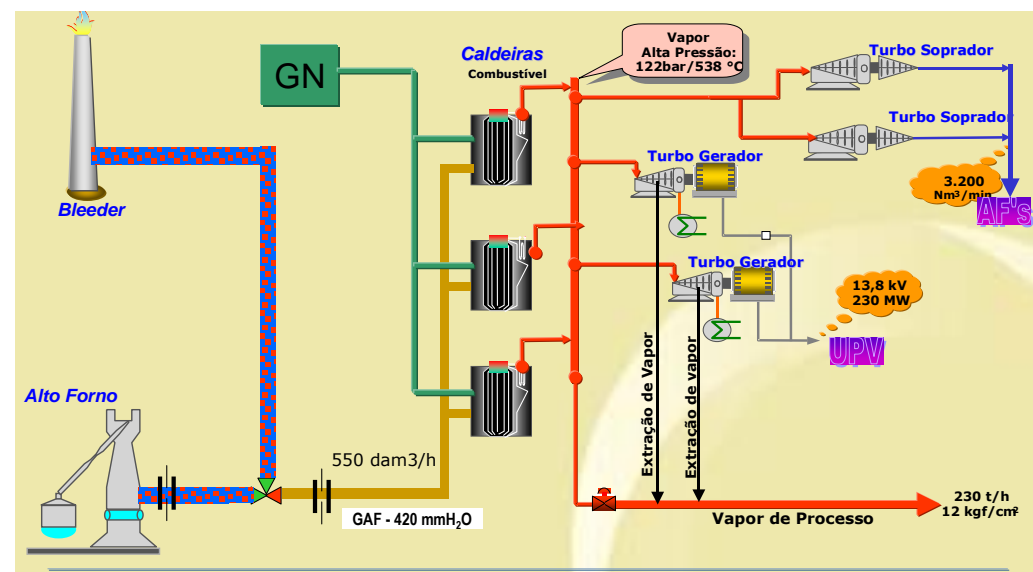

Figura 1. Fluxograma da unidade geradora de energia de $60 \mathrm{~Hz}$.

Este trabalho tem como objetivo apresentar os resultados do aumento de geração na CTE-2, com impacto na redução do custo de Energia elétrica no grupo CSN e produtos da Usina Presidente Vargas.

A necessidade de consumo de energia elétrica na CSN é de $400 \mathrm{MWh}$ médio, sendo composto por 170MWh de Itá, $23 \mathrm{MWh}$ de Igarapava, 60MWh do Mercado e 150 $\mathrm{MWh}$ da CTE-2. Sabemos que nos períodos de novembro a março o custo de energia elétrica torna-se mais caro em função da estiagem e do baixo nível dos reservatórios das hidrelétricas.

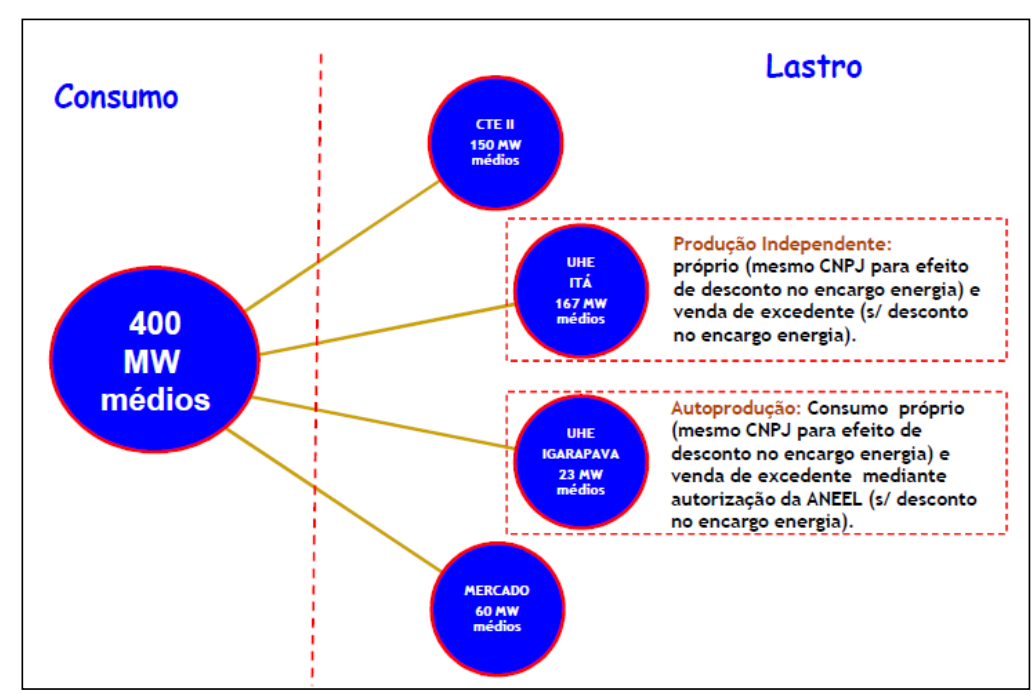

Figura 2. Ilustração do sistema energia da UPV

* Contribuição técnica ao $35^{\circ}$ Seminário de Balanços Energéticos Globais e Utilidades e $29^{\circ}$ Encontro de Produtores e Consumidores de Gases Industriais, 13 a 15 de agosto de 2014, São Paulo, SP, Brasil. 


\section{DESCRIÇÃO DO EQUIPAMENTO DA CTE-2}

A CTE-2 tem uma capacidade de geração máxima de $240 \mathrm{MW} / \mathrm{h}$ para abastecer o sistema de geração de energéticos da UPV, mostrado abaixo na Figura 2, têm as seguintes características:

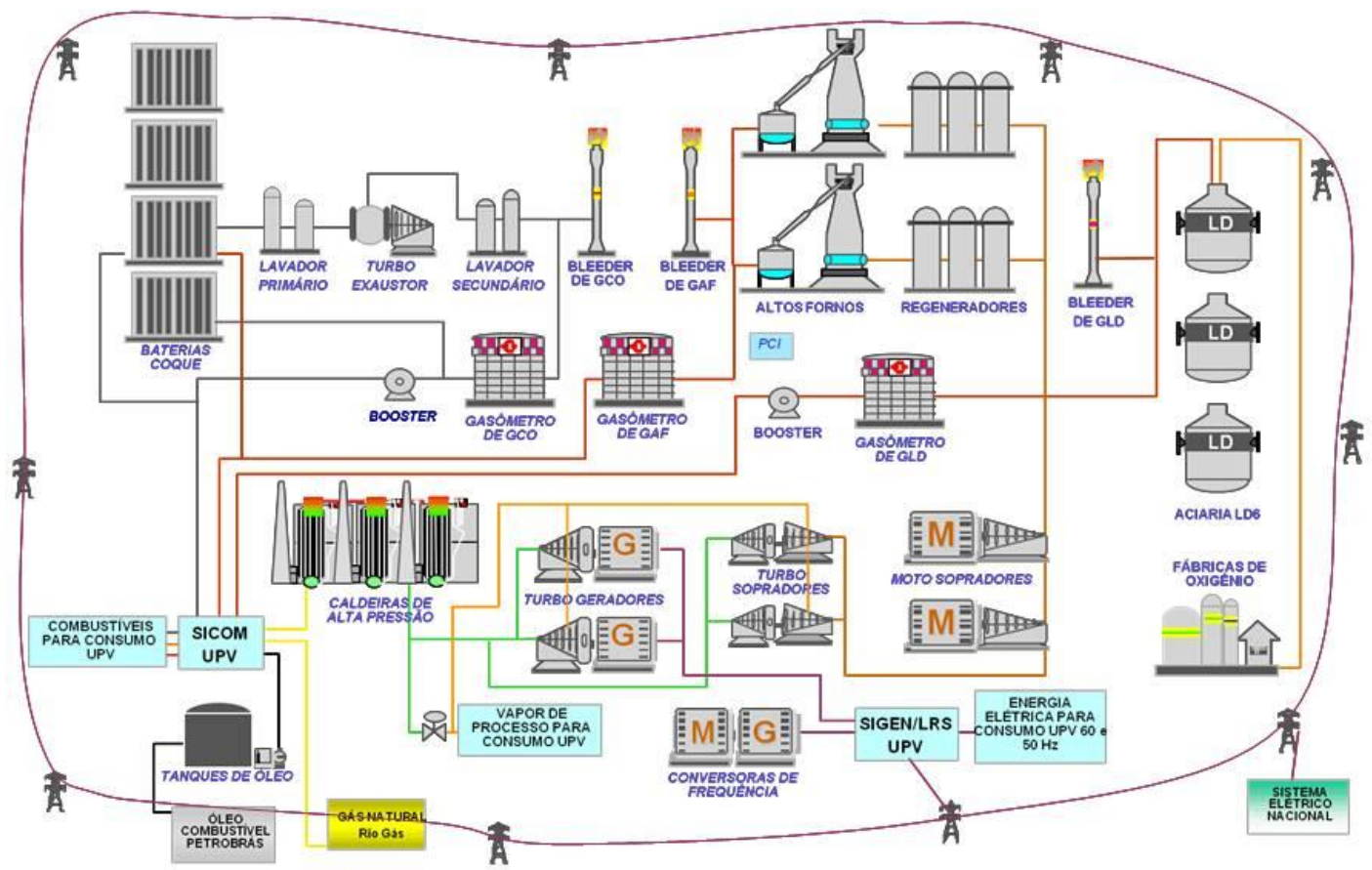

\section{HISTÓRICO}

Figura 3. llustração do sistema de energético da UPV

Através de avaliação dos preços do mercado de curto prazo de energia elétrica em janeiro de 2013, a CSN Energia solicitou a GGCE avaliar a disponibilidade de geração de energia elétrica da CTE-2. Nesta ocasião a CTE-2 operava em modo econômico com mínimo consumo de gás natural.

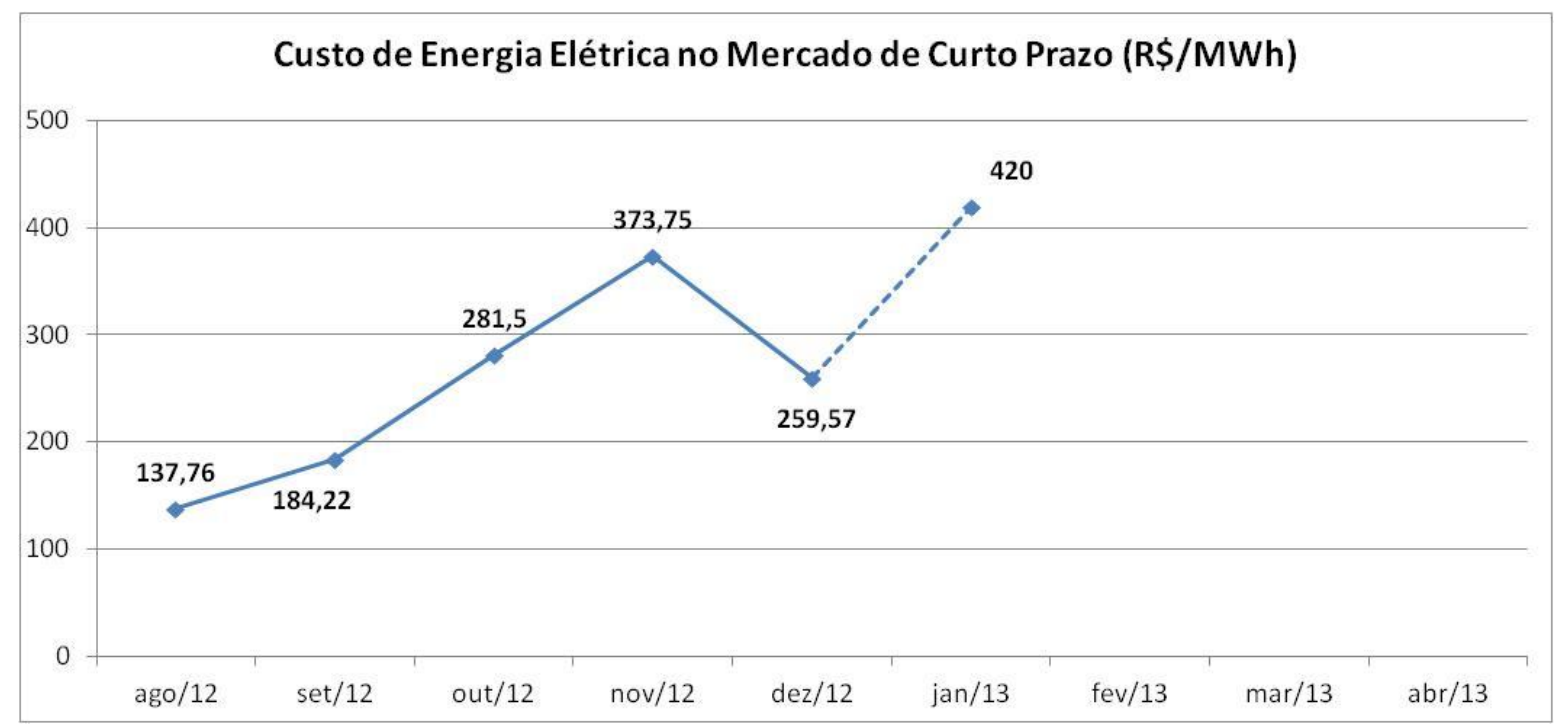

Figura 4. Gráfico de custo de energia elétrica no mercado externo.

* Contribuição técnica ao $35^{\circ}$ Seminário de Balanços Energéticos Globais e Utilidades e $29^{\circ}$ Encontro de Produtores e Consumidores de Gases Industriais, 13 a 15 de agosto de 2014, São Paulo, SP, Brasil. 


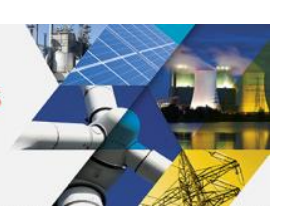

Em função do modo de geração econômica da CTE-2, tínhamos uma disponibilidade de geração. Considerando o estudo realizado da avaliação dos preços do mercado de curto prazo de energia elétrica e esta disponibilidade, vislumbrou-se uma oportunidade de ganho aproximado de $\mathrm{R} \$ 3,3$ milhões/mês.

Logo o grupo começou a desenvolver uma alternativa para viabilizar a implantação de um novo procedimento de geração de energia elétrica na CTE-2.

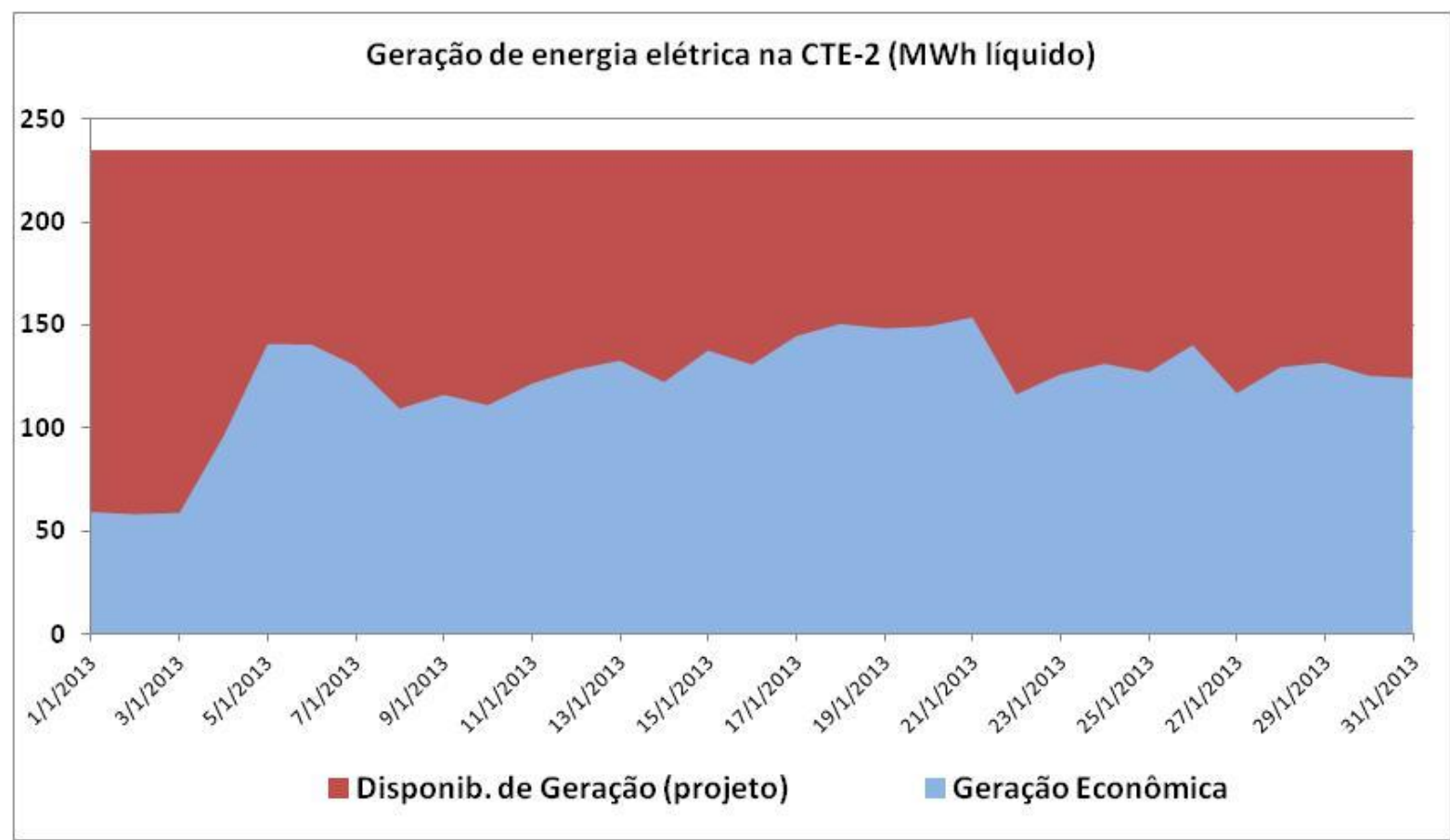

Figura 5. Gráfico de disponibilidade de geração de energia elétrica na CTE-2.

\section{DESENVOLVIMENTO DO ESTUDO}

Com o cenário supracitado, começaram as análises do projeto, verificando os modos de operação e avaliação das condições operacionais.

\subsection{Análise do Projeto}

Com mais de 13 anos de operação, a planta CTE-2 foi projetada para operar com carga de 40\% @ 100\%, com uma carga máxima de 105\%. Cada caldeira tem uma capacidade de carga de $97 \mathrm{Kg} / \mathrm{s}$. Pode se operar por um período de 21 horas por dia no modo waste gás e 3 horas em overpressure.

O sistema de alta pressão e vapor é operado na pressão de 120 bar e em overload de 127 bar e temperatura de $540^{\circ} \mathrm{C}$. O requisito de geração para cada é de 117,5 MW, para um total de geração de $235 \mathrm{MW}$ e vapor de processo de $180 \mathrm{MW}$.

* Contribuição técnica ao $35^{\circ}$ Seminário de Balanços Energéticos Globais e Utilidades e $29^{\circ}$ Encontro de Produtores e Consumidores de Gases Industriais, 13 a 15 de agosto de 2014, São Paulo, SP, Brasil. 

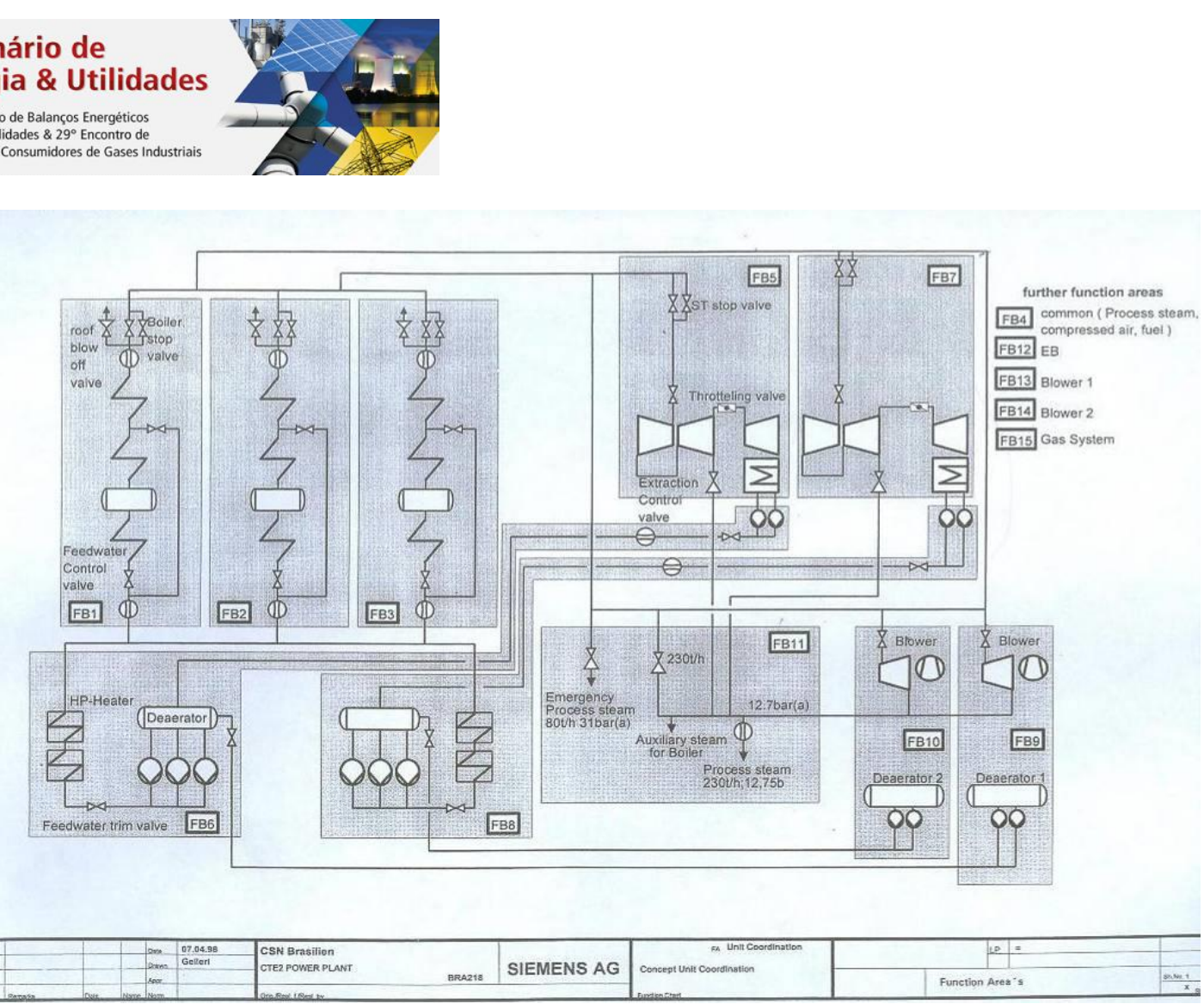

Figura 6. Macro fluxo operacional da CTE-2.

\subsection{Análise do Processo}

O Processo de energéticos da CTE-2 é formado pela geração dos produtos: ar soprado para os Altos Fornos, vapor de processo 12bar, vapor de processo 30bar e energia elétrica. Para geração destes, se faz necessário a absorção de uma grande quantidade de energia na forma de combustíveis internos (GAF, GLD, GCO) e externos de alto valor agregado (GN e ÓLEO). A eficiência da planta é avaliada pela quantidade de energia em gcal dos produtos dividido pela quantidade de energia em gcal dos combustíveis consumidos. Logo, a geração adicional não afetaria as metas já assumidas e sim benefícios aos equipamentos da geração de energéticos.

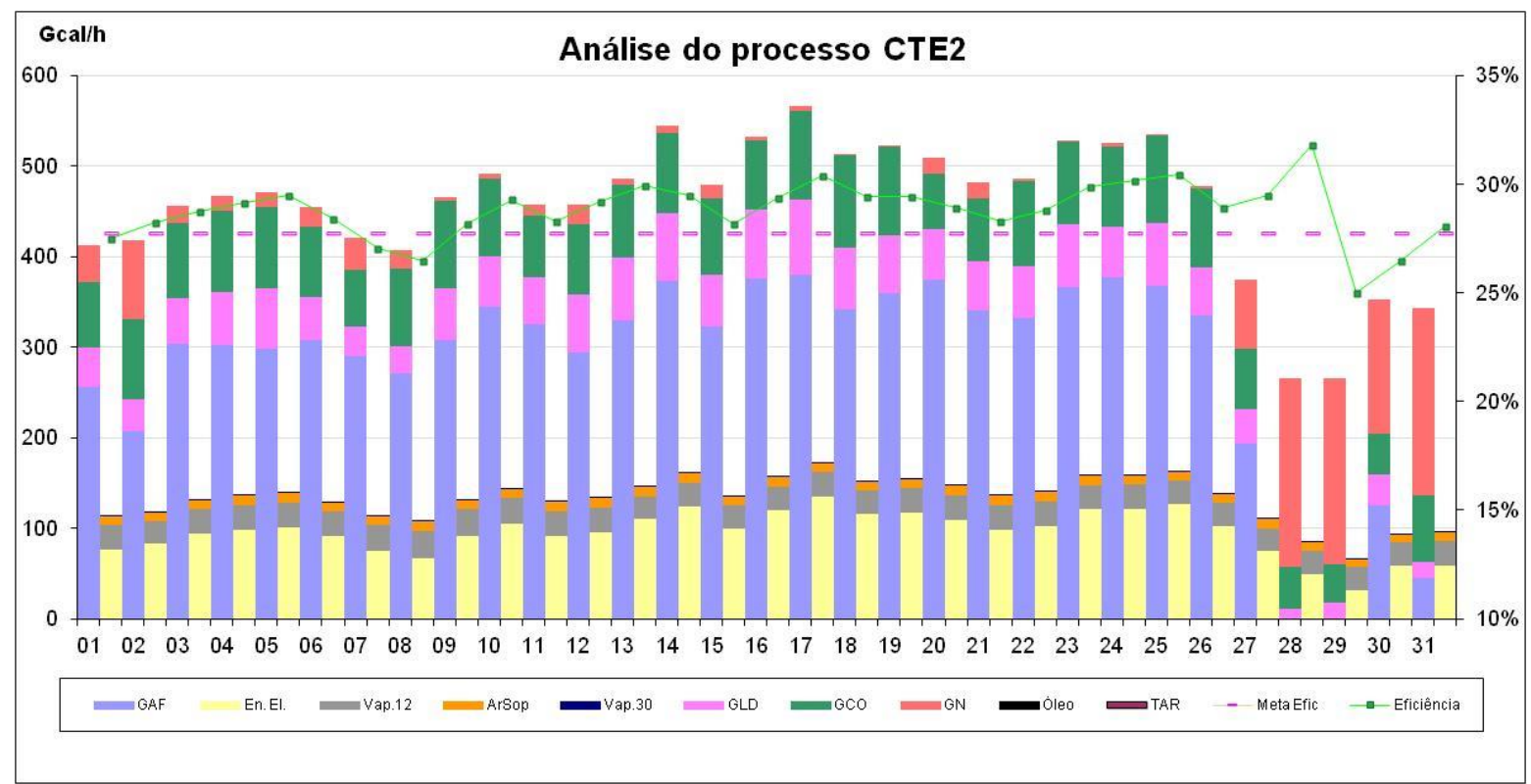

Figura 7. Gráfico de análise de processo da CTE-2.

* Contribuição técnica ao $35^{\circ}$ Seminário de Balanços Energéticos Globais e Utilidades e $29^{\circ}$ Encontro de Produtores e Consumidores de Gases Industriais, 13 a 15 de agosto de 2014, São Paulo, SP, Brasil. 


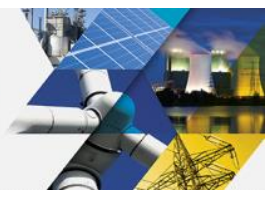

\subsection{Análise da Disponibilidade de Geração de Energia Elétrica na CTE-2}

Devido ao tempo de operação da planta (> 13 anos) iremos avaliar a capacidade eficiente de seus equipamentos. Foi realizado um teste de performance em novembro de 2012 onde concluir os limites de geração e disponibilidade para atendimento do requisito. $O$ teste evidenciou que deveríamos limitar a operação da planta em 200 MWh bruto em função da redução de eficiência nos turbo geradores da CTE-2.

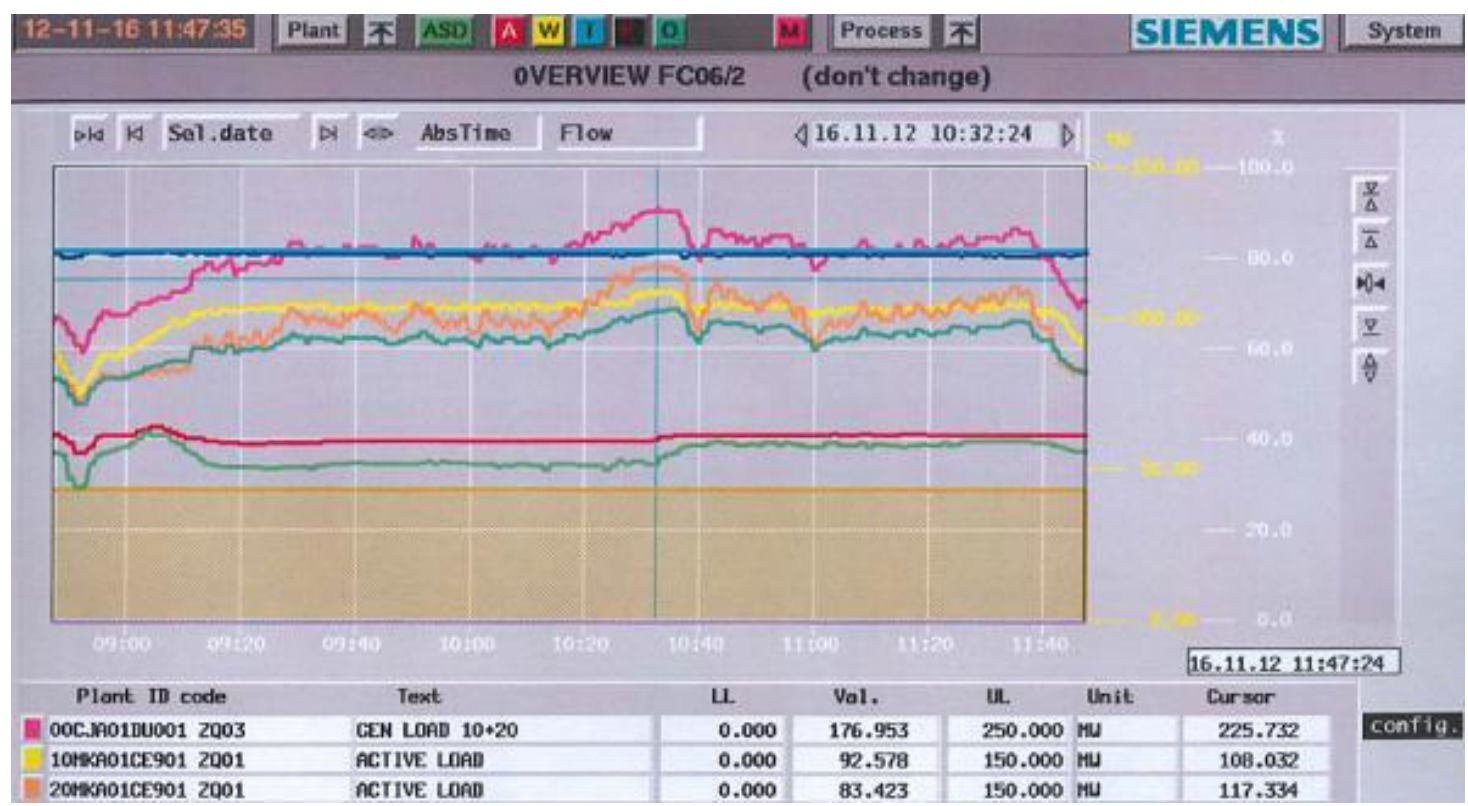

Figura 7. Teste de performance da CTE-2.

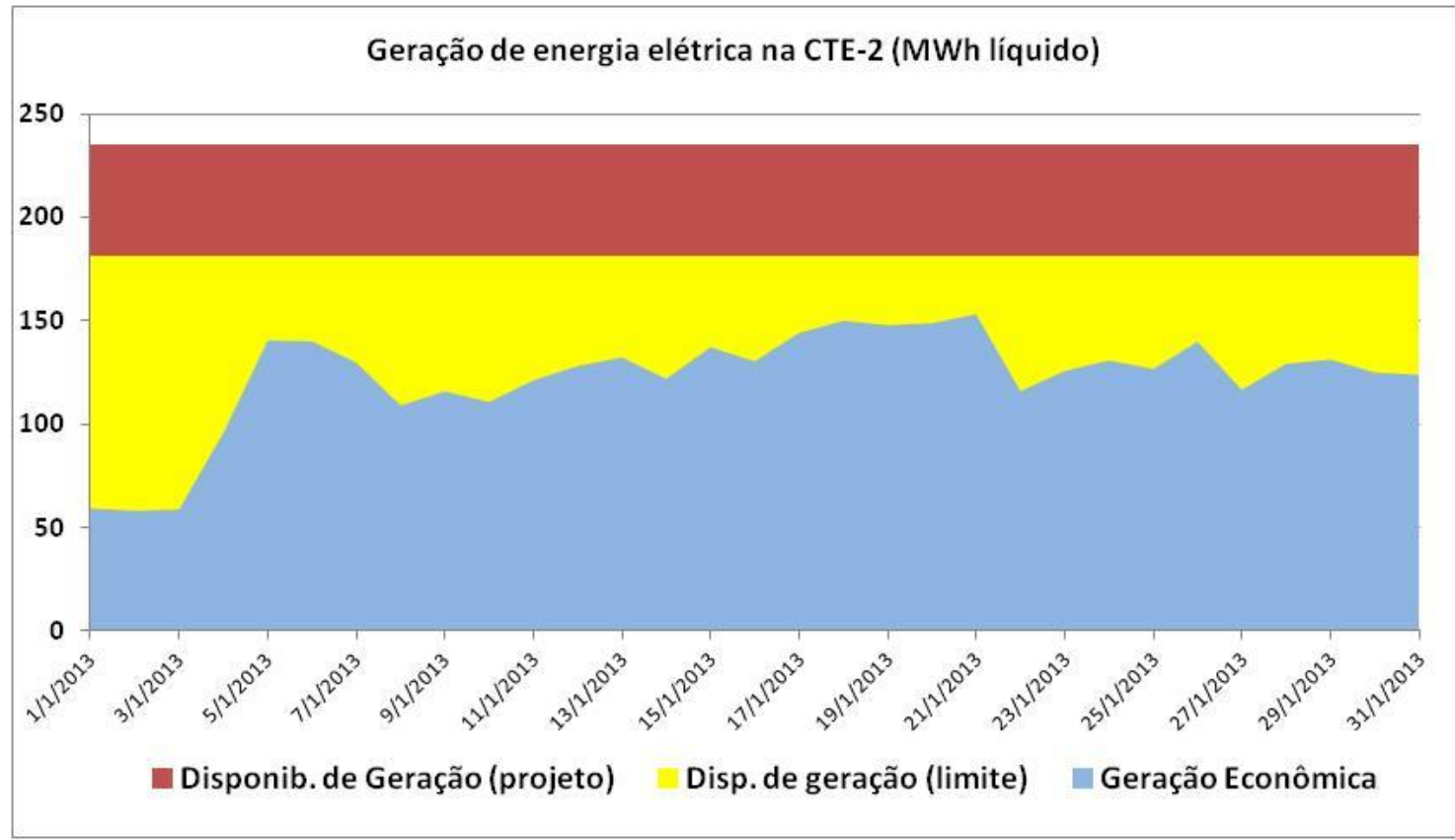

Figura 8. Disponibilidade de geração adicional a geração econômica na CTE-2.

* Contribuição técnica ao $35^{\circ}$ Seminário de Balanços Energéticos Globais e Utilidades e 29० Encontro de Produtores e Consumidores de Gases Industriais, 13 a 15 de agosto de 2014 , São Paulo, SP, Brasil. 


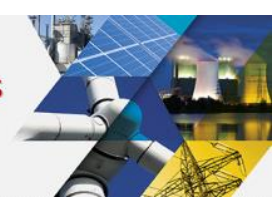

\subsection{Análise do Custo do Gás Natural}

O gás natural é um combustível externo de alto valor agregado, em análise, foi calculado o consumo específico da geração e através de preço unitário histórico de gás natural foi possível definir um valor médio o preço, dividindo o preço médio 828,70 reais pelo consumo específico 3,2 obteve o custo de geração de energia elétrica com gás natural na CTE-2, 259,00 reais por MWh, a esse valor foi acrescentado o custo de $O \& M$ da geração atingindo assim um valor final de 270,00 reais aproximadamente.

Conforme análise apresentada, fica evidente a viabilidade de geração de energia elétrica com gás natural na CTE-2 apenas quando a energia elétrica adquirida no mercado de curto prazo ultrapassar o valor acima citado, devendo levar em consideração uma margem de segurança, uma vez que o preço da energia do mercado de curto prazo é projetado, podendo oscilar para cima ou para baixo

\begin{tabular}{|c|c|c|c|c|c|}
\cline { 2 - 3 } & volume & energia & $\begin{array}{c}\text { Eficiência } \\
\text { CTE-2 }\end{array}$ & $\begin{array}{c}\text { Energia } \\
\text { Efetiva }\end{array}$ & $\begin{array}{c}\text { Consumo } \\
\text { Específico }\end{array}$ \\
\hline GN & 1 dam $^{3}$ & $8,60 \mathrm{gcal}$ & & $2,75 \mathrm{gcal}$ & \multirow{2}{*}{$3,2 \mathrm{MWh} / \mathrm{dam}^{3}$} \\
\cline { 1 - 2 } \cline { 5 - 5 } & $1 \mathrm{MWh}$ & $0,86 \mathrm{gcal}$ & & $0,86 \mathrm{gcal}$ & \\
\hline
\end{tabular}

Figura 9. Cálculo do consumo específico.

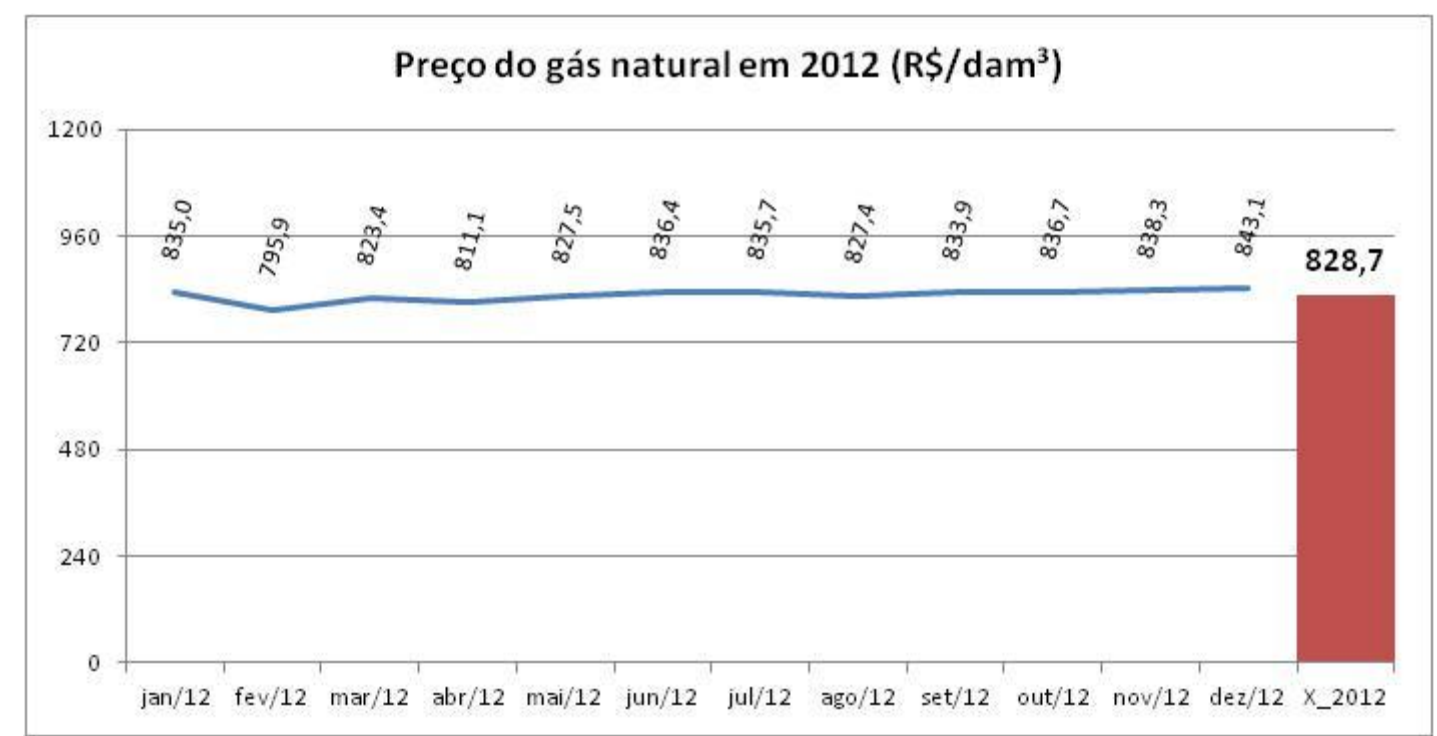

Figura 10. Preço histórico do gás natural.

\subsection{Análise do Mercado de Energia Elétrica}

$\mathrm{Na}$ análise do mercado de energia, entendemos que este tem característica volátil e requer gerenciamento apurado pois é vital para o sucesso do negócio.

O modelo de governança interna da CSN para o gerenciamento de energia no grupo possui participação em ativos de energia elétrica, como Itá e Igarapava, possui também contratos de longo prazo com algumas concessionárias, além da utilização ou disponibilização de energia elétrica no mercado de curto prazo. O montante de energia elétrica dessas fontes forma o lastro de energia disponível para as unidades consumidoras do grupo CSN. A gestão dessa energia fica a cargo da GPG, responsável pela CSN Energia. 

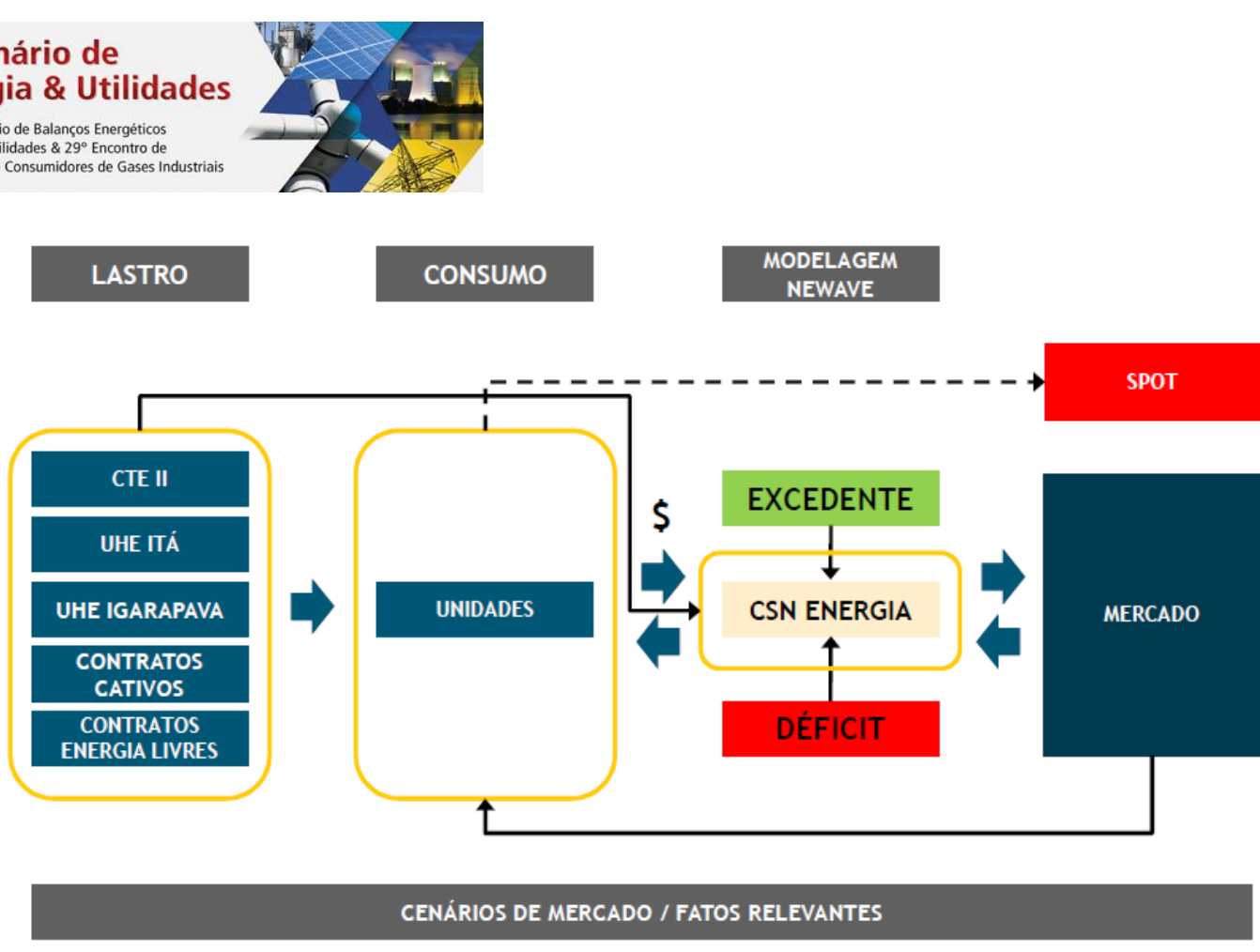

Figura 11. Modelo de negócio simplificado.

Para viabilizar a execução do procedimento de geração de energia elétrica adicional, foi estruturado um modelo de contabilidade de custos da CSN com a criação de um centro de custo (cc4036) para receber o faturamento das fontes de energia elétrica citadas. Neste centro de custo através do lançamento de atividades do SAP/R3, é apurado e repassado às unidades consumidoras proporcional ao consumo de cada uma, no qual a UPV possui uma participação de aproximadamente $85 \%$. O restante fica com Casa de Pedra, Arcos, Portos e CSN Porto Real. O valor repassado a UPV através do cc4036 forma o custo de consumo de energia elétrica externa.

\section{RESULTADOS E DISCUSSÕES}

Análise dos resultados dos exames e testes Figura 11, foram executados seguindo os critérios técnicos, literatura aplicável nos principais conceitos empregados, bases regulatórias e modelo de governança, com foco nos custos competitivos e condições técnicas dos equipamentos (comportamento da condição operacional). Então, podemos afirmar que a geração de energia elétrica adicional com gás natural é viável e tem um expressivo retorno monetário para o grupo CSN.

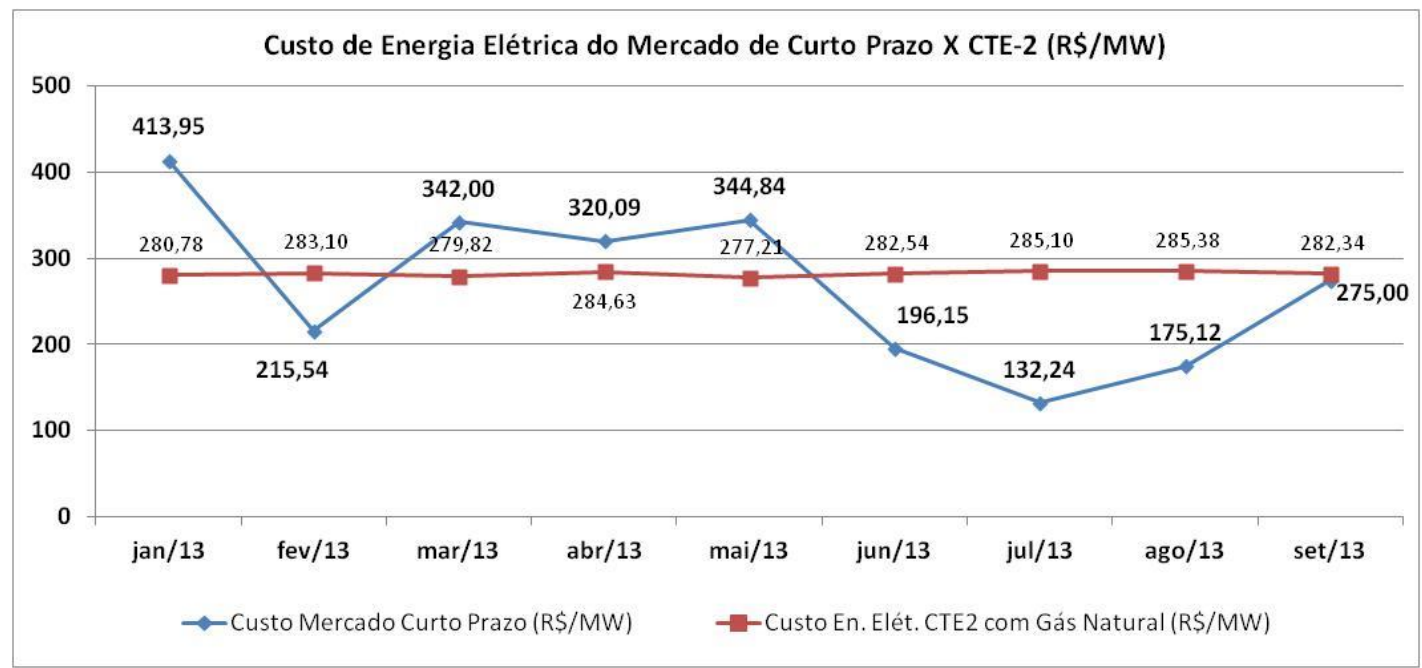

Figura 12. Custo de energia elétrica

* Contribuição técnica ao $35^{\circ}$ Seminário de Balanços Energéticos Globais e Utilidades e $29^{\circ}$ Encontro de Produtores e Consumidores de Gases Industriais, 13 a 15 de agosto de 2014, São Paulo, SP, Brasil. 


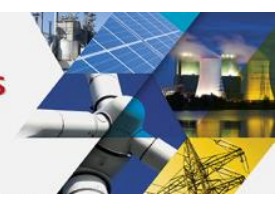

As avaliações executadas e os procedimentos adotados, se mostraram efetivos, uma vez que houve um retorno monetário conforme tabela 2, levando a:

- Redução do custo de energia elétrica para o grupo CSN

- Aumento do rendimento da planta CTE-2

Tabela 1. Gasto total evitado com energia elétrica (ganho)

\begin{tabular}{|c|c|c|c|c|c|c|c|c|c|c|}
\hline & & Janeiro & & Março & & Abril & & Maio & & Junho \\
\hline RECEITA DA VENDA (MCP + INTERNO) (R\$) & $\mathrm{RS}$ & $9.728 .198,18$ & $\mathrm{RS}$ & $5.312 .927,15$ & $\mathrm{R} \$$ & $4.178 .134,12$ & $\mathrm{RS}$ & $10.499 .145,33$ & $\mathrm{RS}$ & $3.062 .557,71$ \\
\hline DESPEZA GERAÇÃO GÁS NATURAL (R\$̧) & $\mathrm{R} \$$ & $(7.113 .890,35)$ & $\mathrm{R} \$$ & $(5.084 .537,64)$ & $\mathrm{R} \$$ & $(4.181 .532,64)$ & $\mathrm{R} \$$ & $(8.764 .230,24)$ & $\mathrm{R} \$$ & $(3.286 .961,12)$ \\
\hline CUSTO EVITADO PARCELA CONSUMIDA (PLDxGN) & $\mathrm{R} \$$ & $759.763,20$ & $\mathrm{RS}$ & $860.574,97$ & $\mathrm{R} \$$ & $(1.247 .239,60)$ & $\mathrm{RS}$ & $403.241,35$ & $\mathrm{R} \$$ & $(647.146,30)$ \\
\hline CUSTO EVITADO COM ENCARGOS SETORIAIS (TUSD) (R\$)) & $\mathrm{R} \$$ & $657.215,45$ & $\mathrm{R} \$$ & $215.868,15$ & $\mathrm{RS}$ & $177.530,35$ & $\mathrm{R} \$$ & $375.595,50$ & $\mathrm{R} \$$ & $138.209,65$ \\
\hline CUSTO EVITADO COM ESS (R\$̣) & $\mathrm{R} \$$ & $332.158,89$ & $\mathrm{R} \$$ & $239.024,25$ & $\mathrm{R} \$$ & $72.564,78$ & $\mathrm{R} \$$ & $96.807,53$ & $\mathrm{R} \$$ & $54.179,81$ \\
\hline CUSTO EVITADO (R\$) ? PLD & $\mathrm{RS}$ & - & $\mathrm{R} \$$ & - & $\mathrm{R} \$$ & $1.847 .378,81$ & $\mathrm{RS}$ & $366.098,46$ & $\mathrm{R} \$$ & $941.842,43$ \\
\hline SUB TOTAL (R\$) & $\mathrm{R} \$$ & $4.363 .445,38$ & $\mathrm{RS}$ & $1.543 .856,88$ & $\mathrm{R} \$$ & $846.835,82$ & $\mathrm{RS}$ & $2.976 .657,94$ & $\mathrm{RS}$ & $262.682,18$ \\
\hline
\end{tabular}

\section{CONCLUSÃo}

Este trabalho mostrou que a metodologia e as ações adotadas pelo Grupo foram eficazes, pois com o desenvolvimento dos estudos conseguiu- se interpretar 0 mecanismo de preços do mercado de curto prazo de energia elétrica e analisar o processo de geração da planta, diagnosticar e definir a melhor configuração operacional.

Os resultados apresentados foram significativos para as condições de geração de energia elétrica adicional com gás natural, o que representa redução do custo de energia elétrica para o grupo CSN e aumento da segurança operacional da planta da CTE2.

\section{REFERÊNCIAS}

1 Torreira RP. Geradores de vapor. Companhia Melhoramentos;1995.

2 Manual de Instalação e Operação SM/BBS - Caldeiras mono drum da Central Termoelétrica 2. Volta Redonda; 1999.

3 Woodruff EB. Steam Plant Operation; Seventh Edition; Hebert B. Lammers; Thomas F. Lammers; Mc Graw - Hill; 1998.

4 American Petroleum Institute. API Risk Based Inspection 581. $1^{\text {st }}$ ed. American Petroleum Institute; 2005. 